\title{
Expansion of the Tonotopic Area in the Auditory Cortex of the Blind
}

\author{
Thomas Elbert, ${ }^{1}$ Annette Sterr, ${ }^{2}$ Brigitte Rockstroh, ${ }^{1}$ Christo Pantev, ${ }^{3}$ Matthias M. Müller, ${ }^{2}$ and \\ Edward Taub 4,5 \\ ${ }^{1}$ Department of Psychology, University of Konstanz, D-78457 Konstanz, Germany, ${ }^{2}$ Department of Psychology, University \\ of Liverpool, Liverpool L69 7ZA, United Kingdom, ${ }^{3}$ Rotman Research Institute for Neuroscience, Toronto, Ontario, \\ Canada M6A 2E1, ${ }^{4}$ Department of Psychology, University of Alabama at Birmingham, Alabama 35294, and ${ }^{5}$ Birmingham \\ Veterans Affairs Medical Center, Birmingham, Alabama 35233
}

A part of the core area of the auditory cortex was examined in nine blind and10 sighted individuals by magnetic source imaging and was found to be enlarged by a factor of 1.8 in the blind compared with the sighted humans. Moreover, the latency of the N1m component of the auditory-evoked magnetic response was significantly decreased in the blind. The development of use-dependent cortical reorganization may be a consequence of the absence of visual input in combination with enhanced

Blind individuals are forced by the nature of their disability to depend on nonvisual modalities, including audition, for information about their external environment. When attention is directed to peripheral auditory space, localization of sounds has been shown to be better in blind than in sighted people (Muchnik et al., 1991; Lessard et al., 1998; Röder et al., 1999a). Data on sound localization in the frontal region (Zwiers et al., 2001) and other auditory discriminative abilities is less conclusive (Stankov and Spilsbury, 1978). Whether or not the full range of auditory perceptual ability is improved in the blind, it is nevertheless the case that sensory input over nonvisual avenues becomes of greater behavioral relevance to these individuals to enable effective interaction with the world around them.

Focused attention on behaviorally relevant stimulation over extended periods has been found to produce a substantial enlargement in the representational zones of the involved portions of the body in somatosensory cortex in research with animals (Merzenich et al., 1984; Jenkins et al., 1990) and humans (Elbert et al., 1994, 1995, 1998; Sterr et al., 1998a,b). Similarly, the primary auditory cortical fields can be dramatically refined or profoundly degraded. Use-dependent reorganization in the frequency receptive fields has been demonstrated by a number of groups (Bakin and Weinberger, 1990; Recanzone et al., 1993; Ohl and Scheich, 1996).

Increasing interest has been devoted to the phenomenon of cross-modal plasticity in blind humans, such that auditory (Kujala et al., 1992, 1995a,b, 1997; Alho et al., 1993; Rösler et al., 1993; Weeks et al., 2000) and tactile (Rösler et al., 1993; Uhl et al., 1993; Kujala et al., 1995b; Röder et al., 1996, 1997; Cohen et al.,

\footnotetext{
Received June 28, 2002; revised Aug. 28, 2002; accepted Sept. 3, 2002.

This study was supported by the Deutsche Forschungsgemeinschaft, the Volkswagenstiftung, and Grants B95-975R and W98 0410 from the Rehabilitation Research and Development Service, United States Department of Veterans Affairs. We thank A. Keil, B. Röder, and F. Rösler for comments on this manuscript.

Correspondence should be addressed to Dr. Thomas Elbert, University of Konstanz, P.O. Box D25, D-78457 Konstanz, Germany. E-mail: thomas.elbert@unikonstanz.de.

Copyright (C) 2002 Society for Neuroscience $\quad 0270-6474 / 02 / 229941-04 \$ 15.00 / 0$
}

auditory activity generated by the long-term concentration by blind individuals on nonvisual cues to interact appropriately with the environment. It is consistent with and well suited to mediate the demonstrated increased ability of the blind to accurately localize acoustic sources in peripheral auditory fields and to decode speech.

Key words: tonotopic map; auditory cortex; reorganization; blind; MEG
1997) stimuli come to be processed in visual cortex. Rauschecker et al. (1992), for instance, found in cats and mice deprived of vision from birth, a supernormal growth of facial vibrissae and an enlarged whisker representation in the somatosensory cortical barrel field. There has been little work evaluating the prediction from the use-dependent cortical reorganization literature that there would be a related but more direct effect, i.e., increased reliance on the auditory modality would give rise to alterations in the auditory areas of the brain. In one relevant experiment, Hamilton et al. (2000) found an increased prevalence of absolute pitch in blind musicians.

The present study explored changes in the auditory cortex of blind individuals as a consequence of the enhanced, visual deprivation-enforced auditory processing. An expansion of regions within the auditory cortex was expected as an indication of use-dependent cortical reorganization. Considering the evidence of the global functional organization of the auditory cortex and its topographic representation of stimulus and processing domains (Rauschecker, 1998; Schreiner, 1998; Rauschecker and Tian, 2000), the tonotopic map can be reconstructed from the auditory magnetic response to pure tones. Recently, Godey et al. (2001) validated the presently used neuromagnetic source localization of auditory-evoked fields with source localization from intracerebral-evoked potentials and demonstrated that both methods suggest that the auditory-evoked N1 may be generated from sources in the intermediate and lateral parts of the Heschl's gyrus and in the planum temporale. The present study, using magnetic source localization, explored whether the increased dependence on the auditory modality in blind individuals would result in an alteration of regions in the auditory cortex.

\section{MATERIALS AND METHODS}

Nine blind (four male, five female; mean age, $39.4 \pm 6.1$; range, 27-46 years) and 10 sighted (five male, five female; mean age, $37.1 \pm 6.8$; range, 29-47 years) subjects participated in the study. Five of the blind subjects were blind from birth; four had become blind as adults between the ages of 16 and 30 years, with their mean duration of blindness being $8.3 \pm 3.8$ years. In all cases, blindness was attributable to peripheral damage of the 
visual system, and there were no additional neurological problems. All subjects were right handed, and audiological examinations indicated a normal status. Informed consent was obtained from each subject after they received a detailed explanation concerning the nature of the study.

Magnetic fields evoked by sequences of acoustic stimuli were recorded simultaneously from the right and left hemispheres using a 148-channel whole-head neuromagnetometer. For recording, subjects were placed in a supine position that was made as comfortable as possible to prevent head and body movement. The recording device (Magnes 2500; 4-D Neuroimaging, San Diego, CA) was operated within a magnetically shielded room. The magnetic sensing devices (magnetometers) were separated by $28 \mathrm{~mm}$ and were arranged in a uniformly distributed array on the inside surface of a helmet.

Four series of 128 tone bursts each were delivered monaurally to the right ear, at $60 \mathrm{~dB}$ above individually determined hearing level. For each series, stimuli had a carrier frequency of $0.5,1,2$, or $4 \mathrm{kHz}$; the sequence of frequencies was randomized across subjects according to a fixed irregular order. Each tone burst was $500 \mathrm{msec}$ in duration, with $10 \mathrm{msec}$ rise and fall time with a cosine slope. Stimuli were presented through a nonmagnetic and echo-free stimulus delivery system $(6.3 \mathrm{~m}$ in length, 16 $\mathrm{mm}$ inner diameter) with an almost linear frequency characteristic (deviations less than $\pm 4 \mathrm{~dB}$ in the range between 200 and $4000 \mathrm{~Hz}$ ). The interstimulus interval varied randomly between 2.7 and $3.3 \mathrm{sec}$.

Stimulus-related epochs were recorded with a bandwidth of 1-100 Hz and sampled at $387.5 \mathrm{~Hz}$. Epochs contaminated by muscle or eye blink artifacts with amplitude variations of $>3 \mathrm{pT}$ in any channel were automatically rejected from additional analysis. The averaged evoked fields were filtered from 1 to $20 \mathrm{~Hz}$ and referred to a $100 \mathrm{msec}$ prestimulus baseline. Source analysis followed the procedure developed by Pantev et al. (1989, 1995, 1998). Subsets of $\sim 40$ channels centered around the source location and including the signal extrema were selected for analysis for the left or the right auditory areas, separately.

When the equivalent current dipole for a given frequency did not match one of the criteria, it was excluded from estimation of the regression line. On the contralateral side, this was the case for one sighted and two blind subjects, and, on the ipsilateral side, it was true for one sighted and three blind subjects. In four subjects (three sighted and one blind), two or more source locations did not match the criteria for a focal source, and, therefore, no regression parameters were computed. Mean residual variance was 1.6 times greater in the blind than in sighted subjects.

\section{RESULTS}

Consistent with previous findings for sighted individuals (Pantev et al., 1988,1989, 1995, 1998; Mäkelä, 1988), the N1m peak occurred at an earlier latency over the contralateral hemisphere than over the ipsilateral hemisphere in both groups (mean contralateral latency across all subjects, $109.3 \pm 17.4$ msec; mean ipsilateral latency, $\left.119.7 \pm 14.3 \mathrm{msec} ; F_{(1,15)}=16.5 ; p<0.01\right)$. In the blind subjects, N1m latencies were consistently shorter than in the sighted subjects $(107.0 \pm 12.4 \mathrm{msec}$ for the blind and $121.40 \pm$ $17.14 \mathrm{msec}$ for the sighted subjects, both hemispheres; $F_{(1,15)}=$ 4.6; $p<0.05)$. This group difference was significant for both the contralateral (16.4 msec) and the ipsilateral (11.8 msec) hemispheres. Frequency did not have a significant effect on N1 latencies (main effect, $p=11$; interactions, all $F$ values $<1$; all mean differences were smaller than $5 \mathrm{msec}$ ).

A dipolar structure for the N1m component was observed over each hemisphere and was similar in blind and sighted individuals. The global field power [root mean square (rms) across subsets of channels] and the $\mathrm{N} 1 \mathrm{~m}$ dipole moment $(\mathrm{Q})$, representing the $\mathrm{N} 1 \mathrm{~m}$ source strength, showed a larger contralateral (rms, $155.8 \pm 76.2$ $\mathrm{fT} ; \mathrm{Q}, 37.9 \pm 29.1 \mathrm{nAm})$ than ipsilateral magnitude (rms, $128.5 \pm$ $54.6 \mathrm{fT} ; \mathrm{Q}, 25.7 \pm 17.6 \mathrm{nAm} ; F_{\mathrm{rms}(1,15)}=14.1 ; p<0.01 ; F_{\mathrm{Q}(1,15)}=$ $14.1 ; p<0.01)$. On average, these measures of N1m amplitude were somewhat larger for the sighted than for the blind subjects, but the difference between blind and sighted subjects with respect to these measures of $\mathrm{N} 1 \mathrm{~m}$ magnitude did not reach significance. For the analysis of the rms, as a measure of signal power, which does not require source modeling, all subjects could be included in
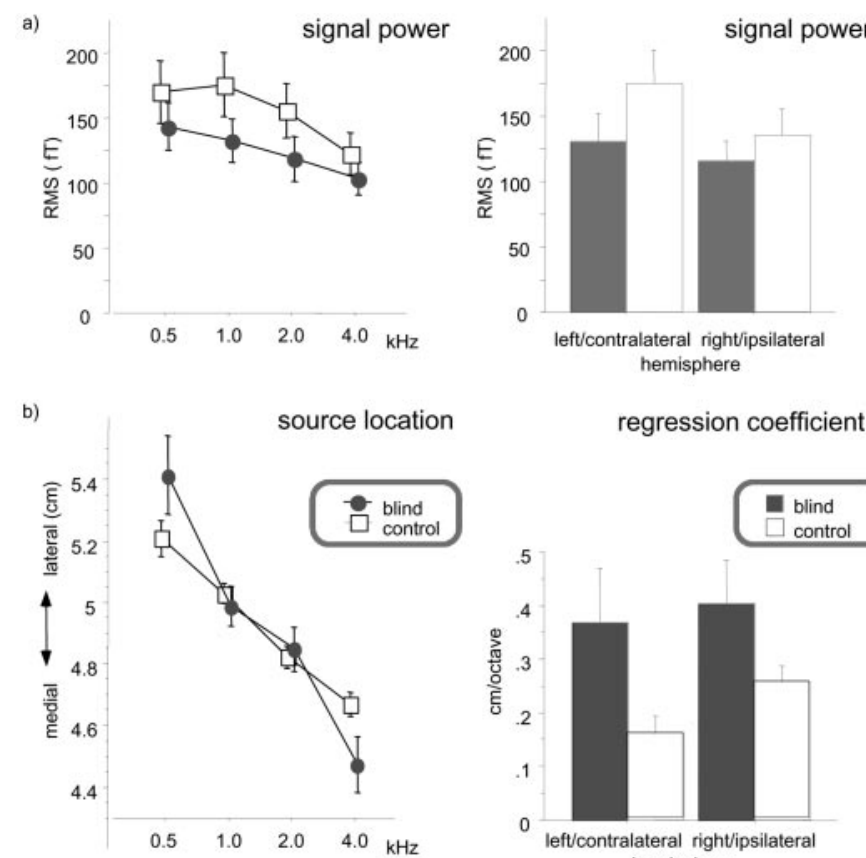

regression coefficient

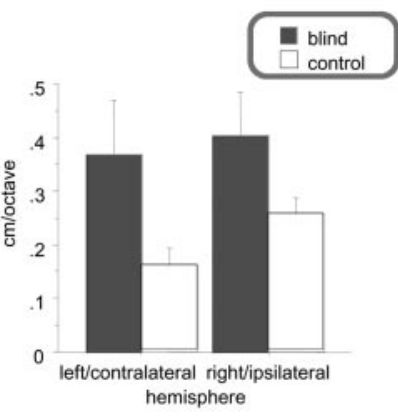

Figure 1. The change in signal power $(a)$ and source location on the mediolateral axis $(b)$ is shown as a function of stimulus frequency, averaged separately for the two groups. The bar graphs on the right illustrate that the effects [smaller signal power (NS) and expanded map size $(p<0.01)$ in the blind] can be observed equally in both hemispheres. The observation that the area across which the four different frequencies respond is larger in the blind whereas the signal power tends to be smaller suggests that the neuronal pool activated by a given sinusoidal tone is more specific in the blind than in sighted individuals. Error bars indicate SEs.

the analysis; there was not a significant main effect of groups $\left(F_{(1,17)}=1.5 ; p=0.24\right)$. A drop of signal power with stimulation frequency (Fig. 1a) was present equally in both groups (main effect for frequency, $\left.F_{(3,51)}=14.2 ; p<0.01\right)$. Figure 1 plots the rms and the N1m source locations against the logarithms of the four standard frequencies used in this experiment for blind and sighted individuals.

The core areas of auditory cortex and adjacent regions exhibit a tonotopic arrangement in humans such that higher frequencies are represented medially and lower frequencies are represented progressively more laterally (Pantev et al., 1988, 1989). When $\mathrm{N} 1 \mathrm{~m}$ dipole locations are plotted against the logarithm of frequency (Fig. 1b), they can be represented (with interpolation) by a straight line (Pantev et al., 1995, 1998). The steeper the slope of this regression line, the more extended is the map of the tonotopic representation. The absolute slope of this regression line for the sighted individuals is 1.84 times steeper than for the blind individuals, indicating that the tonotopic map for blind individuals is $84 \%$ larger in the blind than in sighted $(p=0.001)$ (Fig. $1 b)$. As illustrated in the right panel of Figure $1 b$, this effect was present to the same extent in both hemispheres. When the two regression coefficients were averaged across hemispheres (ignoring missing values from one hemisphere), absolute coefficients were obtained for all 19 subjects; the main effect of group was $F_{(1,17)}=13.2(p<0.01)$. The effect remained significant, when only those five blind and five sighted subjects were included for whom there was a complete set of source models, i.e., a current dipole could be fitted for each frequency in each hemisphere 
$\left(F_{(1,8)}=9.2 ; p<0.02\right)$. The averages of these subgroups were almost identical with the averages across all subjects.

\section{DISCUSSION}

The early research on use-dependent cortical reorganization (Merzenich et al., 1984; Jenkins et al., 1990) indicated that it was the behavioral relevance of afferent input that was responsible for increases in the size of cortical representational zones associated with the reception of that input rather than simply the amount of incoming stimulation. Blind individuals do not receive more auditory stimulation than sighted individuals. However, to interact effectively with their environment, they have to rely on nonvisual, primarily auditory input to a greater extent.

Behavioral relevance as a source of use-dependent reorganization suggests the possibility that the expansion might have some value in the functional economy of the individual. It has been shown that the localization of sounds in peripheral fields (Lessard et al., 1998; Röder et al., 1999a) and other central auditory skills (Muchnik et al., 1991) are better in blind than sighted individuals. This capability should be of value in the blind, who are unable to use vision to discriminate the location of objects and potential avenues for progression. Sound localization is generally considered to be a function of binaural cues processed in the auditory cortex. However, it has been argued (Rauschecker, 1999) that there can be a second set of cues based on specific filtering of sounds by the head and pinnae that provide information concerning the spatial origin of acoustic stimuli. It is possible that the expansion of the tonotopic map in the blind might in some way be involved in providing a basis for the very subtle discriminations that would be required to improve this type of capability. For example, a larger neural network would have a higher fidelity and, consequently, as previously demonstrated, a greater speed at which temporal auditory discriminations could be made. In fact, monaural sound localization is enhanced in the blind (Lessard et al., 1998). Moreover, a more efficient encoding of verbal material (Röder et al., 2001) has been reported. This capability may also be mediated by the enlarged cortical representation given that the frequency spectrum used in the present study covers the sound spectrum of language. Finally, our findings might also explain the shorter refractory periods observed in the blind for the N1 evoked potential component (Röder et al., 1999b).

Previously, we showed in blind individuals that there is an increase and alteration in the functional organization of the area of the cortex receiving somatosensory information (Sterr et al., 1998a,b), and Pascual-Leone and Torres (1993) have shown that a similar phenomenon takes place in motor cortex. Recently, attention has also been focused on the intriguing phenomenon of cross-modal plasticity in blind individuals whereby auditory and somatosensory input comes to be processed in the visual areas in the brain (Rauschecker, 1995; Kujala et al., 2000). These areas have been deprived of their normal source of visual sensory input and might therefore otherwise be unused. We found no activity in the latency range below $120 \mathrm{msec}$ that could be fitted by dipolar sources in visual areas and thus no evidence of short-latency processing of simple auditory input in visual cortex in blind people. However, the auditory map, which we determined had expanded greatly in blind individuals, is situated in the area of the brain that does carry out short-latency processing of auditory input by the nature of its built-in structural connectivity. This is fundamental to later auditory processing, which can involve regions adjacent to primary auditory cortex, as in sighted individuals, and also distant locations, as in the blind.
One plausible explanation of the expansion of auditory cortex in blind individuals found in the present study is the elaboration of a use-dependent cortical reorganization involving either an unmasking of previously silent connections and/or sprouting of new neural elements from those that previously existed. Alternate hypotheses are possible. For example, blindness could lead to reduced cell death in the cortical territory of other modalities, including auditory cortex, or to stabilization of transient connections. It also seems possible that an expanded auditory area might include a larger number of contributing neurons and hence larger dipole moments. Another possibility is that the frequency tuning of neurons might become more frequency specific with the consequence that a tone of a particular frequency would activate a smaller set of neurons; an expansion of the auditory cortex would thus be needed to house more such sets (Bakin and Weinberger, 1990). The mechanisms are not mutually exclusive, and, in some cases, they are partially overlapping; the present data do not permit determination of which were operative. It also remains questionable whether the expanded tonotopic map observed here has a causal relationship to the auditory discrimination abilities observed to be enhanced in the blind noted above.

However, the expansion of the tonotopic map observed in this experiment does supplement the picture of the way in which the brain reorganizes itself in response to blindness, possibly as a result of the blind individuals' greater attention to and reliance on nonvisual sensory avenues to maintain adequate commerce with the world around them. The expansion of the tonotopic map, the reorganization of somatosensory cortex, and cross-modal plasticity in the blind (Rösler et al., 1993; Kujala et al., 1995a, 1997; Sadato et al., 1996; Cohen et al., 1997; Sterr et al., 1998a,b) would appear to be an excellent composite example of the principle formulated by Merzenich et al. (1984) of the continual competition for cortical space. When there is increased use of a body part of type of sensory discrimination, the representational zones within the brain normally responsible for mediating those functions expand at the expense of other regions that are currently not being used to the same extent.

\section{REFERENCES}

Alho K, Kujala T, Paavilainen P, Summala H, Näätänen R (1993) Auditory processing in visual brain areas of the early blind: evidence from event-related potentials. Electroencephalogr Clin Neurophysiol $86: 418-427$.

Bakin JS, Weinberger NM (1990) Calssical conditioning induces CSspecific receptive field plasticity in the auditory cortex of the guinea pig. Brain Res 536:271-286.

Cohen LG, Celnick P, Pascual-Leone A, Corwell B, Faiz L, Dambrosia J, Honda M, Sadato N, Gerloff C, Catala MD, Hallett M (1997) Functional relevance of cross-model plasticity in blind humans. Nature 389:180-183.

Elbert T, Flor H, Birbaumer N, Knecht S, Hampson S, Taub E (1994) Extensive reorganization of the somatosensory cortex in adult humans after nervous system injury. NeuroReport 5:2593-2597.

Elbert T, Pantev C, Wienbruch C, Rockstroh B, Taub E (1995) Increased use of the left hand in string players associated with increased cortical representation of the fingers. Science 270:305-307.

Elbert T, Candia V, Altenmüller E, Rau H, Sterr A, Rockstroh B, Pantev C, Taub E (1998) Alteration of digital representations in somatosensory cortex in focal hand dystonia. NeuroReport 16:3571-3575.

Godey B, Schwartz D, de Graaf JB, Chauvel P, Liégeois-Chauvel C (2001) Neuromagnetic source localization of auditory evoked fields and intracerebral evoked potentials: a comparison of data in the same patients. Clin Neurophysiol 112:1850-1859.

Hamilton RH, Pascual-Leone A, Rodriguez D, Schlaug G (2000) Increased prevalence of absolute pitch in blind musicians. Soc Neurosci Abstr 26:739.13.

Jenkins WM, Merzenich MM, Ochs MT, Allard T, Guic-Robles E (1990) Functional reorganisation of primary somatosensory cortex in adult owl monkeys after behaviorally controlled tactile stimulation. J Neurophysiol 63:82-104. 
Kujala T, Alho K, Paavilainen P, Summala H, Näätänen R (1992) Neuronal plasticity in processing of sound location by the early blind: an event-related potential study. Electroencephalogr Clin Neurophysiol $84: 469-472$.

Kujala T, Huotilainen M, Snikkonen J, Ahonen, AI, Alho K, Hämäläinen MS, Ilmoniemi RJ, Kajola M, Knuutila JET, Lavikainen J, Salonen O, Simola J, Standertskjöld-Nordenstam CG, Näätänen R (1995a) Visual cortex activation in blind humans during sound discrimination. Neurosci Lett 183:143-146.

Kujala T, Alho K, Kekoni J, Hämäläinen MS, Reinikainen K, Salonen O, Standertskjöld-Nordenstam CG, Näätänen R (1995b) Auditory and somatosensory event-related brain potentials in early blind humans. Exp Brain Res 104:519-526.

Kujala T, Alho K, Huotilainen M, Ilmoniemi RJ, Lehtokoki A, Leinonen A, Rinne T, Salonen O, Snikkonen J, Standertskjöld-Nordenstam C-G, Näätänen R (1997) Electrophysiological evidence for cross-modal plasticity in humans with early- and late-onset blindness. Psychophysiology 34:213-216.

Kujala T, Alho K, Näätänen R (2000) Cross-modal reorganization of human cortical functions. Trends Neurosci 23:115-120.

Lessard N, Paré M, Lepore F, Lassonde M (1998) Early-blind human subjects localize sound sources better than sighted subjects. Nature 395:278-280.

Mäkelä JP (1988) Contra- and ipsilateral auditory stimuli produce different activation patterns at the human auditory cortex: a neuromagnetic study. Pflügers Arch 412:12-16.

Merzenich MM, Nelson RJ, Stryker MP, Cynader MS, Schoppmann A, Zook JM (1984) Somatosensory cortical map changes following digit amputation in adult monkeys. J Comp Neurol 224:591-605.

Muchnik C, Efrati M, Nemeth E, Malin M, Hildesheimer M (1991) Central auditory skills in blind and sighted subjects. Scand Audiol 20:19-23

Ohl F, Scheich H (1996) Differential frequency conditioning enhances spectral contrast sensitivity of units in auditory cortex (field $\mathrm{Al}$ ) of the alert Mongolian gerbil. Eur J Neurosci 96:100-117.

Pantev C, Hoke M, Lehnertz K, Lütkenhöner B, Anogianakis G, Wittkowski W (1988) Tonotopic organization of the human auditory cortex revealed by transient auditory evoked magnetic fields. Electroencephalogr Clin Neurophysiol 69:160-170.

Pantev C, Hoke M, Lütkenhöner B, Lehnertz K (1989) Tonotopic organization of the auditory cortex: pitch versus frequency representation. Science 246:486-488.

Pantev C, Bertrand O, Eulitz C, Verkindt C, Hampson S, Schuirer G, Elbert T (1995) Specific tonotopic organizations of different areas of human auditory cortex revealed by simultaneous magnetic and electric recordings. Electroencephalogr Clin Neurophysiol 94:26-40.

Pantev C, Ross B, Berg P, Elbert T, Rockstroh B (1998) Study of the human auditory cortices using a whole-head magnetometer: left vs. right hemisphere and ipsilateral vs. contralateral stimulation. Audiol Neurootol 3:183-190.

Pascual-Leone A, Torres F (1993) Plasticity of the sensorimotor cortex representation of the reading finger in Braille readers. Brain 116:39-52.

Rauschecker JP (1995) Compensatory plasticity and sensory substitution in the cerebral cortex. Trends Neurosci 18:36-43.
Rauschecker JP (1998) Cortical processing of complex sounds. Curr Opin Neurobiol 8:516-521.

Rauschecker JP (1999) Auditory cortical plasticity: a comparison with other sensory systems. Trends Neurosci 22:74-80.

Rauschecker JP, Tian B (2000) Mechanisms and streams for processing of "what" and "where" in auditory cortex. Proc Natl Acad Sci USA 97:11800-11806.

Rauschecker JP, Tian B, Korte M, Egert U (1992) Crossmodal changes in the somatosensory vibrissa/barrel system of visually deprived animals. Proc Natl Acad Sci USA 89:5063-5067.

Recanzone GH, Schreiner CE, Merzenich MM (1993) Plasticity in the frequency representation of primary auditory cortex following discrimination training in adult owl monkeys. J Neuroscience 13:87-103.

Röder B, Rösler F, Henninghausen E, Näcker F (1996) Event-related potentials during auditory and somatosensory discrimination in sighted and blind human subjects. Cogn Brain Res 4:77-93.

Röder B, Rösler F, Henninghausen E (1997) Different cortical activation patterns in blind and sighted humans during encoding and transformation of haptic images. Psychophysiology 34:292-307.

Röder B, Teder-Sälejärvi W, Sterr A, Rösler F, Hillyard SA, Neville HJ (1999a) Improved auditory spatial tuning in blind humans. Nature 400:162-166.

Röder B, Rösler F, Neville HJ (1999b) Effects of interstimulus interval on auditory event-related potentials in congenitally blind and normally sighted humans. Neurosci Lett 264:53-56.

Röder B, Rösler F, Neville HJ (2001) Auditory memory in congenitally blind adults: a behavioral-electrophysiological investigation. Cogn Brain Res 11:289-303.

Rösler F, Röder B, Heil M, Hennighausen E (1993) Topographic differences of slow event-related brain potentials in blind and sighted adult human subjects during haptic mental rotation. Cogn Brain Res 1:145-159.

Sadato N, Pascual-Leone A, Grafman J, Ibanes V, Deiber MP, Dold G, Hallett M (1996) Activation of the primary visual cortex by Braille reading in blind subjects. Nature 380:527-528.

Schreiner CE (1998) Spatial distribution of responses to simple and complex sounds in the primary auditory cortex. Audiol Neurootol 3:104-122.

Stankov L, Spilsbury G (1978) The measurement of auditory abilities of blind, partially sighted, and sighted children. Appl Psychol Meas 2:491-503.

Sterr A, Müller MM, Elbert T, Rockstroh B, Taub E (1998a) Changed perceptions in Braille readers. Nature 391:134-135.

Sterr A, Müller MM, Elbert T, Rockstroh B, Pantev C, Taub E (1998b) Perceptual correlates of changes in cortical representation of fingers in blind multifinger Braille readers. J Neurosci 18:4417-4423.

Uhl F, Franzen P, Podreka I, Steiner M, Deecke L (1993) Increased regional cerebral blood flow in inferior occipital cortex and cerebellum of early blind humans. Neurosci Lett 150:162-164.

Weeks R, Horwitz B, Aziz-Sultan A, Tian B, Wessinger CM, Cohen LG, Hallett M, Rauschecker JP (2000) A positron emission tomographic study of auditory localization in the congenitally blind. J Neurosci 20:2664-2672.

Zwiers MP, Van Opstal AJ, Cruysberg JRM (2001) A spatial hearing deficit in early-blind humans. J Neurosci 21:RC142(1-5). 